\title{
PENGGUNAAN OBAT GASTRITIS GOLONGAN PROTON PUMP INHIBITOR PADA PASIEN RAWAT JALAN DI RUMAH SAKIT LABUANG BAJI MAKASSAR 2021
}

\author{
La Sakka \\ STIKES Nani Hasanuddin Makassar \\ email: Lasakka01@yahoo.com/085240447237
}

\begin{abstract}
ABSTRAK
Penelitian ini bertujuan untuk mengetahui pola penggunaan obat golongan proton pump inhibitor pada pada pasien rawat jalan di RSUD Labuang Baji provinsi Sulawesi selatan. Jenis penelitian ini adalah penelitian deskriptif dengan pendekatan studi kasus yang bertujuan untuk memperoleh gambaran mengenai obat gastritis golongan proton pump inhibitor. Sampel penelitian adalah semua resep di apotek rawat jalan yang mengandung obat golongan proton pump inhibitor (PPI) dan dihitung jumlah obat yang diberikan pada pasien rawat jalan pada bulan Maret-Mei 2021. Hasil penelitian yaitu obat golongan Proton Pump Inhibitor (PPI) yang paling banyak digunakan adalah Omeprazol 64.88\% dan Lanzoprazol 35.12\% sedangkan Pantoprazol, Rabeprazol dan Esomeprazol sama sekali tidak digunakan. Peresepan obat golongan proton pump inhibitor terbanyak dari poliklinik yaitu poli interna dan kardiologi penyakit dalam dengan persentase $42.06 \%$ dan $28.56 \%$ sedangkan poli anak sama sekali tidak meresepkan obat golongan proton pump inhibitor (PPI). Hal ini dikarenakan poli interna adalah spesialis medis yang berhubungan dengan berbagai penyakit dan masalah kesehatan yang mempengaruhi organ-organ bagian dalam salah satunya lambung.
\end{abstract}

\section{Kata Kunci :Obat Gastritis, Proton Pump Inhibitor, Pasien Rawat}

\section{PENDAHULUAN}

Pelayanan kefarmasian adalah suatu pelayanan langsung dan bertanggung jawab kepada pasien yang berkaitan dengan sediaan farmasi dengan maksud mencapai hasil yang pasti untuk meningkatkan mutu kehidupan pasien. Hal tersebut diperjelas dalam Keputusan Menteri Kesehatan Nomor 72 Menkes 2016 tentang standar pelayanan kefarmasian di rumah sakit, yang menyebutkan bahwa untuk meningkatkan mutu pelayanan kefarmasian di rumah sakit yang berorientasi kepada keselamatan pasien, diperlukan suatu standar yang dapat digunakan sebagai acuan dalam pelayanan kefarmasian (Kemenkes, 2016).

Kegiatan penggunaan obat dan perbekalan kesehatan/ farmasi yang rasional, dilakukan dengan cara meminimalkan efek terapi obat, meminimalkan resiko atau efek samping terapi, meminimalkan biaya pengobatan dan menghormati pasien (Setya , 2016).

Obat adalah bahan atau paduan bahan, termasuk produk biologi yang digunkan untuk mempengaruhi atau menyelidiki system fisiologi atau keadaan patologi dalam rangka penetapan diagnosis, pencegahan, penyembuhan, pemulihan, peningkatan kesehatan dan kontrasepsi untuk manusia. Salah satu obat yang paling banyak diresepkan di seluruh dunia yaitu obat golongan protonpump inhibitor (PPI) (Kemenkes, 2016).

Lambung sebagai salah satu organ yang penting
Gastritis adalah proses inflamasi pada lapisan mukosa dan sub mukosa pada lambung yang merupakan salah satu penyakit yang banyak dijumpai diklinik dengan kerusakan intrgritas mukosa lambung seperti dalam kasus gastritis dan tukak peptik (Tandi, 2017).

Obat-obatan penghambat asam telah digunakan dalam terapi penyakit asam-peptik, yang ditandai dengan terjadinya erosi atau ulserasi pada mukosa saluran cerna atas karena kadar asam-peptik meningkat dan mengganggu pertahanan intrinsik saluran cerna. Jenis penyakit yang masuk dalam asam peptik ini antara lain Gastroesofageal Reflux Disease (GERD), Esofagitis Erosif, dispepsia, dan ulkus peptikum. Golongan penghambat pompa proton (PPI) merupakan contoh obat penghambat asam yang paling sering diresepkan di seluruh dunia. Efikasi dan profil keamanan yang baik, serta adanya rekomendasi berbagai guideline ( Laksmi, 2020 )

Dimedan angka kejadian infeksi cukup tinggi sebesar 91,6\%, dan berdasarkan penelitian angka rata-rata kejadian sakit lambung dirumah sakit cipto mangunkusumo (RSCM) (Sani, 2016).

Berdasarkan data yang diperoleh dari Bidang Bina Pelayanan Kesehatan Dinas Kesehatan Kota Makassar pada tahun 2015 gastritis merupakan salah satu dari 10 besar penyakit penyebab utama kematian di kota Makassar. angka kejadian gastritis dengan prevelensi 35.159 dengan jumlah penduduk 1.449.401 jiwa penduduk, dimana angka tersebut menunjukkan terjadinya peningkatan dari tahun 
sebelumnya. Demikian pula dengan penyakit yang disebabkan oleh gangguan sekresi asam lambung yang lainnya seperti Dyspepsia, Tukak lambung dan GERD (Dinkes, 2015).

Terjadinya peningkatan jumlah penduduk yang mengalami gangguan sekresi asam lambung akan berpengaruh terhadap penggunaan obat yang bekerja dengan cara menekan asam lambung.

Penghambat pompa proton $(\mathrm{PPI}=$ proton pump inhibitors) adalah salah satu obat yang umum diresepkan pada gangguan lambung. Sejak diperkenalkan pada akhir tahun 1980-an, PPI menghasilkan efek penekanan terhadap sekresi asam lambung yang lebih superior dibandingkan penghambat reseptor histamin H2. Penggunaan PPI meningkat dalam tatalaksana berbagai gangguan asam-lambung, termasuk refluks gastroesofageal (GERD), tukak lambung, dan gastropati akibat NSAID. PPI memiliki efek samping lebih minimal dan interaksi terhadap obat-obat lain yang lebih rendah. Secara umum, penggunaannya untuk jangka panjang juga dianggap aman (Panggabean, 2017). Hingga tahun 2015, ada enam jenis PPI yang telah disetujui oleh FDA. Penggunaan PPI telah diadopsi secara luas di kalangan penyedia layanan kesehatan primer. Obat ini terutama menjadi pilihan pertama untuk pengobatan esofagitis, nonerosive reflux disease (NERD), peptic ulcer disease (PUD), pencegahan ulkus terkait pengunaan obat antiinflamasi nonsteroid (NSAID), sindrom Zollinger-Ellison (ZES), dan dispepsia fungsional.PPI juga dapat dikombinasikan dengan antibiotik untuk eradikasi Helicobacter pylori (Panggabean, 2017).

\section{METODE}

\section{Jenis Penelitian}

Jenis penelitian yang dilakukan adalah penelitian deskriptif berdasarkan data-data yang sudah ada tanpa melakukan perlakuan terhadap subyek uji untuk memperoleh gambaran penggunaan golongan obat PPI pada pasien rawat jalan di RSUD Labuang Baji Makassar.

\section{Tempat dan Waktu Penelitian}

Penelitian ini telah dilakukan di apotek rawat jalan Rumah Sakit Umum Daerah Labuang Baji Makassar pada tanggal 15 Maret-10 Mei 2021.

\section{Populasi dan Sampel Penelitian}

Populasi penelitian yaitu resep dengan jumlah 1500 sampai 2,100 perbulan. Sampel penelitian yaitu semua resep di apotek rawat jalan yang mengandung obat golongan proton pump inhibitor (PPI) pada bulan Maret - Mei 2021.

\section{Jenis dan Sumber Data}

Data Primer yang diperoleh di apotek rawat jalan RSUD Labuang Baji Makassar selama 3 bulan yaitu bulan Maret sampai dengan bulan Mei 2021.

\section{Pengumpulan Data}

Dikumpulkan semua resep yang masuk di apotek rawat jalan RSUD Labuang Baji Makassar pada bulan Maret - Mei 2021. Dipilih resep yang mengandung obat proton pump inhibitor (PPI) dan dihitung jumlah obat yang diberikan pada pasien rawat jalan.

\section{Cara Pengolahan Data}

Data yang diperoleh diolah secara manual dan ditabulasikan dalam bentuk tabel. Data yang diperoleh dianalisis secara deskriptif, yaitu membuat gambaran mengenai suatu keadaan secara obyektif yang meliputi :
1. Jenis Kelamin
2. Umur
3. Jenis obat
4. Dosis obat
5. Cara pemberian obat

\section{HASIL PENELITIAN}

Berdasarkan hasil penelitian yang telah dilakukan mengenai profil penggunaan obat golongan proton pump inhibitor (PPI) pada pasien rawat jalan di RSUD Labuang Baji Makassar pada periode Maret - Mei 2021, maka didapatkan data sebagai berikut :

Tabel 1 Jumlah pasien yang mendapatkan obat golongan proton pump inhibitor (PPI) berdasarkan jenis kelamin.

\begin{tabular}{|c|c|c|c|c|c|}
\hline Jenis Kelamin & Maret & April & Mei & Jumlah & $\%$ \\
\hline Laki-laki & 76 & 93 & 85 & 254 & 42.91 \\
\hline Perempuan & 123 & 120 & 95 & 338 & 57.09 \\
\hline Total & 199 & 213 & 180 & 592 & 100 \\
\hline
\end{tabular}

Berdasarkan data pada tabel 1 menunjukkan bahwa jumlah pasien yang mendapat obat golongan proton pump inhibitor (PPI) berdasarkan jenis kelamin di apotek rawat jalan RSUD Labuang baji Makassar pada periode Maret - Mei 2021 sebanyak 592 pasien yang didominasi oleh perempuan dan laki-laki. 
Tabel 2 Jumlah pasien yang mendapatkan obat golongan proton pump inhibitor (PPI) berdasarkan tingkat penddidikan.

\begin{tabular}{|l|c|c|}
\hline Tingkat Pendidikan & $\mathrm{n}$ & $\%$ \\
\hline SD & 18 & 3,04 \\
\hline SMP & 191 & 32,26 \\
\hline SMA & 246 & 41,55 \\
\hline Sarjana & 137 & 23,14 \\
\hline Total & $\mathbf{5 9 2}$ & $\mathbf{1 0 0 , 0 0}$ \\
\hline
\end{tabular}

Berdasarkan data pada tabel 2 diatas dapat disimpulkan tingkat pendidikan pasien yang diresepkan obat golongan proton pump inhibitor yaitu tingkat pendidikan SMA sebagai jumlah terbanyak dengan total 246 orang dan persentase 41,55\%. Untuk pendidikan SD dan SMP sebanyak 18 dan 191 orang dengan persentase 3,04\% dan $32,26 \%$. Pendidikan Sarjana sebanyak 137 orang dengan persentase $23,14 \%$.

Tabel 3 Jumlah pasien yang mendapatkan obat golongan proton pump inhibitor (PPI) berdasarkan status pernikahan

\begin{tabular}{|l|c|c|}
\hline Status Pernikahan & $\mathrm{n}$ & $\%$ \\
\hline Nikah & 298 & 50,34 \\
Belum Nikah & 294 & 49,66 \\
\hline Total & 592 & 100,00 \\
\hline
\end{tabular}

Berdasarkan tabel 3 diatas dapat disimpulkan bahwa status responden yang telah menikah sebanyak 298 responden $(50,34)$ sedangkan yang belum menikah sebanyak 294 responden $(49,66)$.

Tabel 4 Jumlah pasien yang mendapatkan obat golongan proton pump inhibitor (PPI) berdasarkan poli klinik.

\begin{tabular}{|l|c|c|c|c|c|}
\hline Poliklinik & Maret & April & Mei & $\mathrm{n}$ & $\%$ \\
\hline Saraf & 23 & 19 & 26 & 68 & 11.49 \\
\hline Interna & 96 & 91 & 62 & 249 & 42.06 \\
\hline THT & 4 & 10 & 7 & 21 & 3.54 \\
\hline Kardiologi & 62 & 59 & 48 & 169 & 28.54 \\
\hline Kandungan & 2 & 3 & 1 & 6 & 1.01 \\
\hline Jiwa & 4 & 5 & 0 & 9 & 1.52 \\
\hline Bedah urologi & 4 & 2 & 2 & 8 & 1.35 \\
\hline Mata & 1 & 5 & 0 & 6 & 1.01 \\
\hline Orthopedi & 1 & 1 & 10 & 12 & 2.02 \\
\hline VCT & 1 & 0 & 0 & 1 & 0.17 \\
\hline Paru-Paru & 1 & 18 & 22 & 41 & 6.93 \\
\hline Fisiotherapi & 0 & 0 & 1 & 1 & 0.17 \\
\hline Gigi & 0 & 0 & 1 & 1 & 0.17 \\
\hline Anak & 0 & 0 & 0 & 0 & 0 \\
\hline Total & 199 & 213 & 180 & 592 & 100 \\
\hline
\end{tabular}

Berdasarkan tabel 4 menunjukkan bahwa poli yang yang paling banyak meresepkan obat golongan proton pump inhibitor yaitu pada poli klinik interna yaitu sebanyak $42.06 \%$ dan yang sama sekali tidak diresepkan di poli klinik anak.

Tabel 5 Persentase jumlah obat golongan protonpump inhibitor (PPI)

\begin{tabular}{|l|c|c|c|c|c|}
\hline Nama obat & Januari & Februari & Maret & Jumlah & $\%$ \\
\hline Omeprazole & 1336 & 1330 & 1464 & 4130 & 64.88 \\
\hline Lansoprazole & 949 & 793 & 494 & 2236 & 35.12 \\
\hline Pantoprazole & 0 & 0 & 0 & 0 & 0 \\
\hline Rabeprazole & 0 & 0 & 0 & 0 & 0 \\
\hline Esomeprazole & 0 & 0 & 0 & 0 & 0 \\
\hline Total & 2285 & 2123 & 1958 & 6366 & 100 \\
\hline
\end{tabular}

Berdasarkan data pada Tabel 5 menunjukkan bahwa obat golongan proton pump inhibitor (PPI) yang paling banyak digunakan yaitu Omeprazole dengan persentase 64.88\%. 


\section{PEMBAHASAN}

Berdasarkan penelitian yang telah dilakukan mengenai profil penggunaan obat golongan Proton Pump Inhibitor (PPI) periode Maret - Mei 2021 pada pasien rawat jalan di RSUD Labuang Baji Makassar, maka diperoleh hasil bahwa jumlah pasien yang mendapatkan terapi obat golongan proton pump inhibitor (PPI) pada periode tersebut sebanyak 592 pasien yang didominasi oleh perempuan yaitu sebanyak $57.09 \%$ (338 orang) sedangkan laki-laki sebanyak 42.91\% (254 orang) data selengkapnya dapat dilihat pada tabel 1 Tingkat pendidikan sampel yang diambil bervariasi mulai dari tingkat pendidikan Sekolah Dasar (SD) dengan jumlah 18 orang dengan persentase 3,04\%. Tingkat pendidikan SMP dan Sarjana terbanyak kedua dengan jumlah sampel 191 orang untuk tingkat Sekolah Menengah Pertama (SMP) dengan persentase $32,26 \%$ dan pada Tabel 3 diatas didapatkan data jumlah pasien berdasarkan status pernikahan yaitu sebanyak 298 orang sudah menikah dengan persentase $50,34 \%$, sedangkan yang belum menikah sebanyak 294 orang dengan persentase $49,66 \%$.

Sarjana (S1) dengna jumlah sampel 137 orang dengan persentase $23,14 \%$. Tingkat pendidikan terbanyak pada pasien adalah Sekolah Menengah Atas (SMA) yang berjumlah 246 orang dengan persentase $41,55 \%$. Status pernikahan pasien yaitu sebanyak 298 orang sudah menikah dengan persentase $50,34 \%$ dan pasien yang belum menikah sebanyak 294 orang dengan persentase 49,66\%. Adapun faktor penyebab penderita penyakit yang disebabkan sekresi asam lambung pada perempuan lebih banyak dibandingkan laki-laki yaitu karena perempuan lebih mudah stres dan memiliki pola diet yang salah. Selain itu juga bisa disebabkan oleh mekanisme hormonal.

Poliklinik yang paling banyak meresepkan obat golongan proton pump inhibitor (PPI) yaitu poli interna dan poli kardiologi dengan persentase $42.06 \%$ dan $28.56 \%$ sedangkan poli anak sama sekali tidak meresepkan obat golongan Proton Pump Inhibitor (PPI) data selengkapnya dapat dilihat pada tabel 2. Hal ini dikarenakan poli interna adalah spesialisasi medis yang berhubungan dengan berbagai penyakit dan masalah kesehatan yang mempengaruhi organ-organ bagian dalam salah satunya lambung, berdasarkan indikasi obat golongan proton pump inhibitor (PPI) yang diindikasikan untuk penyakit yang disebabkan oleh gangguan sekresi asam lambung. Sedangkan pada poli kardiologi juga banyak diresepkan obat golongan proton pump inhibitor (PPI) dikarenakan pada penyakit jantung koroner banyak meresepkan obat asam asetilsalisilat yang digunakan untuk pencegahan dan pengobatan berbagai keadaan trombosis atau agregasi platelet (pembekuan darah) yang terjadi pada tubuh terutama pada saat mengalami serangan jantung atau pasca stroke. Dimana efek samping asam asetilsalisilat yaitu dapat menyebabkan terjadinya tukak lambung dan pendarahan pada lambung. Jadi obat golongan proton pump inhibitor (PPI) digunakan untuk mengatasi efek samping dari obat asam asetil salisilat.

Jenis obat golongan proton pump inhibitor (PPI) yang paling banyak digunakan yaitu Omeprazole dengan persentase $64.88 \%$, lansoprazole dengan persentase $35.12 \%$. Sedangkan pantoprazole, rabeprazole dan esomeprazole sama sekali tidak digunakan. Data selengkapnya dapat dilihat pada tabel 3 Omeprazole merupakan jenis penghambat pompa proton yang paling besar penggunaannya. Hal ini sesuai dengan kajian penggunaan obat yang dilakukan pada rumah sakit pendidikan di chongqing. China pada tahun 2010 sesuai teori omeprazole merupakan pilihan utama karena harganya murah dan walaupun setiap jenis penghambat pompa proton memiliki profil farmakokinetik berbeda yang dapat mempengaruhi onset kerja dan durasi hambatan terhadap asam pada beberapa hari pertama terapi. Perbedaan tersebut tidak memiliki makna klinis yang besar setelah obat diberikan secara berkesinambungan setiap hari. Faktor lain yang menyebabkan tingginya penggunaan omeprazole yaitu stok obat yang tersedia banyak sehingga pihak instalasi farmasi bekerja sama dengan dokter untuk meresepkan obat tersebut.

Berdasarkan hasil analisis diatas dapat diketahui bahwa banyaknya penggunaan obat golongan proton pump inhibitor (PPI) di apotek rawat jalan RSUD Labuang Baji Makassar sehingga membutuhkan perhatian lebih dari segi perencanaan dan pengadaan obat.

\section{KESIMPULAN}

Berdasarkan hasil penelitian yang telah dilakukan, maka dapat disimpulkan bahwa jenis obat golongan Proton Pump Inhibitor (PPI) yang paling banyak digunakan pada pasien rawat jalan di Rumah Sakit Umum Daerah Labuang Baji yaitu Omeprazol $64.88 \%$, Lansoprazoll $35.12 \%$ sedangkan rabeprazole, pantoprazole dan esomeprazole tidak terdapat penggunaannya. Adapun obat golongan Proton Pump Inhibitor (PPI) yang terbanyak digunakan berdasarkan poliklinik yaitu terdapat pada poli interna dengan persentase yaitu $42.06 \%$ dan yang tidak terdapat penggunaan sama sekali yaitu pada poli anak 


\section{SARAN}

1. Bagi pihak rumah sakit, agar melakukan pemantaun terhadap ketersedian obat golongan proton pump inhibitor (PPI).
2. Bagi peneliti selanjutnya, agar dapat melakukan penelitian terhadap penggunaan obat golongan proton pump inhibitor (PPI) dengan analisa ketepatan indikasi.

\section{DAFTAR PUSTAKA}

Bertram G. Katzung, 2015. Basic and Clinical Pharmacology. McGraw-Hill Enducation.

Dinkes, 2014. Profil Rumah Sakit Umum Daerah Labuang Baji Makassar, (online), (http://www.rsudlbsulsel.co.id, di akses 20April 2018).

Dinkes, 2015. Profil Kesehatan Kota MakassarTahun 2015. Pemerintah Kota Makassar : Makassar.

Gunawan, S G. 2012.Farmakologi dan TerapiEdisi 5. Penerbit Balai Penerbit FKUI :Jakarta.

Herlambang, 2016. Manajemen PelayananKesehatan Rumah Sakit. : Yogyakarta.

Kemenkes, 2016. Peraturan Menteri Kesehatan Republik Indonesia No. 72 Tahun 2016 Tentang Standar Pelayanan Kefarmasian Di Rumah Sakit : Jakarta.

Laksmi Putri, Nashinta and Oktianti, Dian and Minarsih, Tri. 2020. KETIDAKTEPATAN INDIKASI PENGGUNAAN OBAT GOLONGAN PROTON PUMP INHIBITOR PADA INSTALASI RAWAT INAP RUMAH SAKIT. S1 thesis, Universitas Ngudi Waluyo.

Panggabean, S. 2017. Tinjauan atas Pantoprazole Proton Pump Inhibitor. Medical Department PT Kalbe Farma Tbk. Jakarta.

Rikomah Setya, 2016. Farmasi Klinik. Halaman 17Deepublish publisher.

Siregar Charles, J, P dan Amalia L. 2012. Farmasi Rumah Sakit Teori dan Penerapan. Penerbit EGC : Jakarta.

Sudoyo Aru, Alwi Idrus. 2009. Buku Ajar Ilmu Penyakit Dalam. Fakultas Kedokteran Universitas Indonesia. Interna Publishing : Jakarta.

Sumarsono Tonny, 2015. Pengantar Studi Farmasi : jakarta.

Joni Tandi, 2017. Tinjauan Pola Pengobatan Gastristis Pada Pasien Rawat Inap RSUD Luwuk,STIFA Pelita Mas Palu.

Tjay, T. H ; Rahardja, K. 2013. Obat-Obat Penting .PT Elex Media Komputindo : Jakarta.

Tjay, T. H ; Rahardja, K, 2015. Obat-Obat Penting. PT Elex Media Komputindo : Jakarta. 